\title{
Imminent Earthquake Forecasting on the Basis of Japan INTERMAGNET Stations, NEIC, NOAA and Tide Code Data Analysis
}

\author{
Strachimir Cht. Mavrodiev \\ Institute for Nuclear Research and Nuclear Energy, BAS, Sofia, Bulgaria \\ Email: schtmavr@yahoo.com
}

Received 21 December 2015; accepted 23 February 2016; published 26 February 2016

Copyright (C) 2016 by author and Scientific Research Publishing Inc.

This work is licensed under the Creative Commons Attribution International License (CC BY). http://creativecommons.org/licenses/by/4.0/

(c) () D Den Access

\begin{abstract}
This research presents one possible way for imminent prediction of earthquakes' magnitude, depth and epicenter coordinates by solving the inverse problem using a data acquisition network system for monitoring, archiving and complex analysis of geophysical variables-precursors. Among many possible precursors the most reliable are the geoelectromagnetic field, the boreholes water level, radon earth-surface concentration, the local heat flow, ionosphere variables, low frequency atmosphere and Earth core waves. The title demonstrates that only geomagnetic data are used in this study. Within the framework of geomagnetic quake approach it is possible to perform an imminent regional seismic activity forecasting on the basis of simple analysis of geomagnetic data which use a new variable $S_{C h t M}$ with dimension surface density of energy. Such analysis of Japan Memambetsu, Kakioka, Kanoya INTERMAGNET stations and NEIC earthquakes data, the hypothesis that the "predicted" earthquake is this with biggest value of the variable $S_{C h t M}$ permits to formulate an inverse problem (overdetermined algebraic system) for precursor's signals like a function of earthquake's magnitude, depth and distance from a monitoring point. Thus, in the case of data acquisition network system existence, which includes monitoring of more than one reliable precursor variables in at least four points distributed within the area with a radius of up to $700 \mathrm{~km}$, there will be enough algebraic equations for calculation of impending earthquake's magnitude, depth and distance, solving the overdetermined algebraic system.
\end{abstract}

\section{Keywords}

Earthquake's Prediction, Reliable Earthquake's Precursors, Geomagnetism, Inverse Problem

\section{Introduction}

It is well known now that the "when, where and how" earthquake's prediction problem cannot be solved by a 
only analyzing the earthquakes data base [1]-[5].

The role of the Sun-Moon Earth tides as possible earthquake's trigger has been analyzed in [6]-[13]. However the conclusion that the earthquake's time is correlated with the time of tidal extremes is not exact, because in some cases the beginning and the extremes of earthquakes do not coincide. There is an extreme but not an earthquake.

The role of the atmospheric and ionosphere electromagnetic phenomena which can serve as earthquake's precursors in the last time has been researched in many studies. Physical models of the observed phenomena were proposed in [14] and reliability of predictions was analyzed in [15] [16].

The heat released as earthquake's precursor was researched in [17].

The variations of regional water-level reflect fast deformational cycles in lithosphere and may also serve as an earthquake's precursor as one was demonstrated by G.S. Vartanyan [18]. The comparison of the daily geomagnetic fluctuations (geomagnetic quakes) and underground water level demonstrates that borehole water level data may serve as an imminent regional earthquake's precursor in the Caucasus region [19].

The analysis of data for radon concentrations and its fluctuations in the atmosphere and ground-water has been demonstrated in many studies (see [19] [21]). The most accepted result is that anomalous (increased regional concentration) of the radon emission can serve as a precursor of an earthquake.

The research of the correlation between variations of geo-electromagnetic field and impending earthquakes has a long-time history [22]-[36].

A comparative analysis of the two measured values in time of geomagnetic field with the calculation of the standard deviation (dispersion) in the same subintervals-periods of time allowed offering geomagnetic quake as an earthquake precursor [36].

The calculation of the differences (DayDiff) between the times of the earthquakes occurred in the region around the monitoring point and the nearest time of tide extremes permit to build the distribution of DayDiff. It was established that this distribution is described well by Gauss curve with a certain width $\boldsymbol{W}_{\text {all }}$.

Introducing a new variable $S_{C h t M}$ with dimension surface energy density, which is a function of earthquake's magnitude, depth and distance to the monitoring point

$$
S_{\text {ChtM }}(\text { Mag, Depth, Distance) }
$$

and the calculation of its value in the monitoring point permits to classify the earthquakes occurred in the monitoring region and in the time period around tide extremes time.

The distribution of DayDiff for earthquakes with the biggest value of $S_{C h t M}$ is also described with Gauss curve, but with less width $W_{p r}$.

In the paper [37] the DayDiff for all world's 62,8873 earthquakes, occurred in the period 1981-2013, with Mag >= 3 (International Seismological Centre, http://www.isc.ac.uk/) was calculated and the distribution, described by Gauss curve with width $W_{\text {all }}=4.46+/-0.22$.

The distributions of DayDiff for earthquakes with the biggest $S_{C h t M}$ calculation from the data of INTERMAGNET stations PAG (Panagurichte, BAS, Bulgaria, 1 January 2008 to 19 January 2013), SUA (SUA, Romania, 1 January 2008 to 17 January 2013) and AQU (L'Aquila, Italy, 1 January 2008 to 30 May 2013) were described by Gauss curves with widths $4.22+/-0.62,4.11+/-0.51$ and $4.28+/-0.67$. So, one can say that the appearance of geomagnetic quake forecasts that in the next period around time of tide extreme and monitoring point region means an increase in the seismic activity.

There is a simple intuitive physical explanation [36] [38] of the fact that a geomagnetic quake is an earthquake's precursor:

- The increase of the strain before an earthquake is accompanied by electrochemical and electrokinetic effects which generate electrical currents in the epifocal volume;

- These currents, which can be identified using the geomagnetic quake approach.

The earthquake's preparing continues as follow:

- The preliminary stage of an earthquake is accompanied by negative divergence of the energy due to increased dissipation of tidal waves;

- The maximum of two time daily tides' acceleration leads to the transformation of this non-equilibrium state to a new balance that is closer to bifurcation, which explains the role of tides as an earthquake's trigger.

There is the hope that including the above described research of regional precursors in the common approach 
for solving the earthquake prediction problem (see the paper [39] and references there) will lead us to a solution.

In Section 2 is describing the approach for forecasting of imminent regional seismic activity on the basis of Japan geomagnetic data and Sun-Moon Earth tide to de data. In Section 3 is demonstrated the reliability of geomagnetic quake approach for the regions $(700 \mathrm{~km})$ of Memambetsu, Kakioka, Kanoya stations. In Section 4 is presented the description of precursor signal as a function of earthquake's magnitude, depth and distance. In Section 5 is presented the formulation of inverse problem for forecasting the magnitude, depth and epicenter coordinates of regional imminent earthquake

In Application 1, Table 2 is present data for the stations, earthquake's date, latidude, longitude, depth, magnitude, the value of $\boldsymbol{S}_{C h t M}\left[\mathrm{~J} / \mathrm{km}^{2}\right]$, the distance from station $[\mathrm{km}]$, the difference between the predicted time and the time of occurred earthquake [day], the values of experimetal and model precursor signal and its difference (Expt-Th). Aplication 2 is presented the FORTRAN version of precursor signal function PrecSigTh (Mag, Depth, Distance).

\section{Forecasting of Imminent Japan Regional Seismic Activity on the Basis of Geomagnetic and Sun-Moon Earth Tide Code Data}

In this paragraph the data acquisition system for archiving, visualization and analysis is presented [36]-[38].

\subsection{Description of the Approach-Figure 1}

The data used:

- The Japan INTERMAGNET geomagnetic stations MMB (Memambetsu, Lat $43.907^{\circ} \mathrm{N}$, Lon $144.193^{\circ} \mathrm{E}, \mathrm{Al}-$ titude $=42 \mathrm{~m}$ ), KAK $\left(\right.$ Kakioka, Lat $36.232^{\circ} \mathrm{N}$, Lon $140.186^{\circ} \mathrm{E}$, Altitude $\left.=36 \mathrm{~m}\right) \mathrm{KNY}\left(\right.$ Kanoya, Lat $31.42^{\circ} \mathrm{N}$, Lon $130.88^{\circ} \mathrm{E}$, Altitude $=107 \mathrm{~m}$ ) minute data (http://www.intermagnet.org/);

Kakioka, Japan diurnal geomagnetic and earthquake monitoring (700 km)

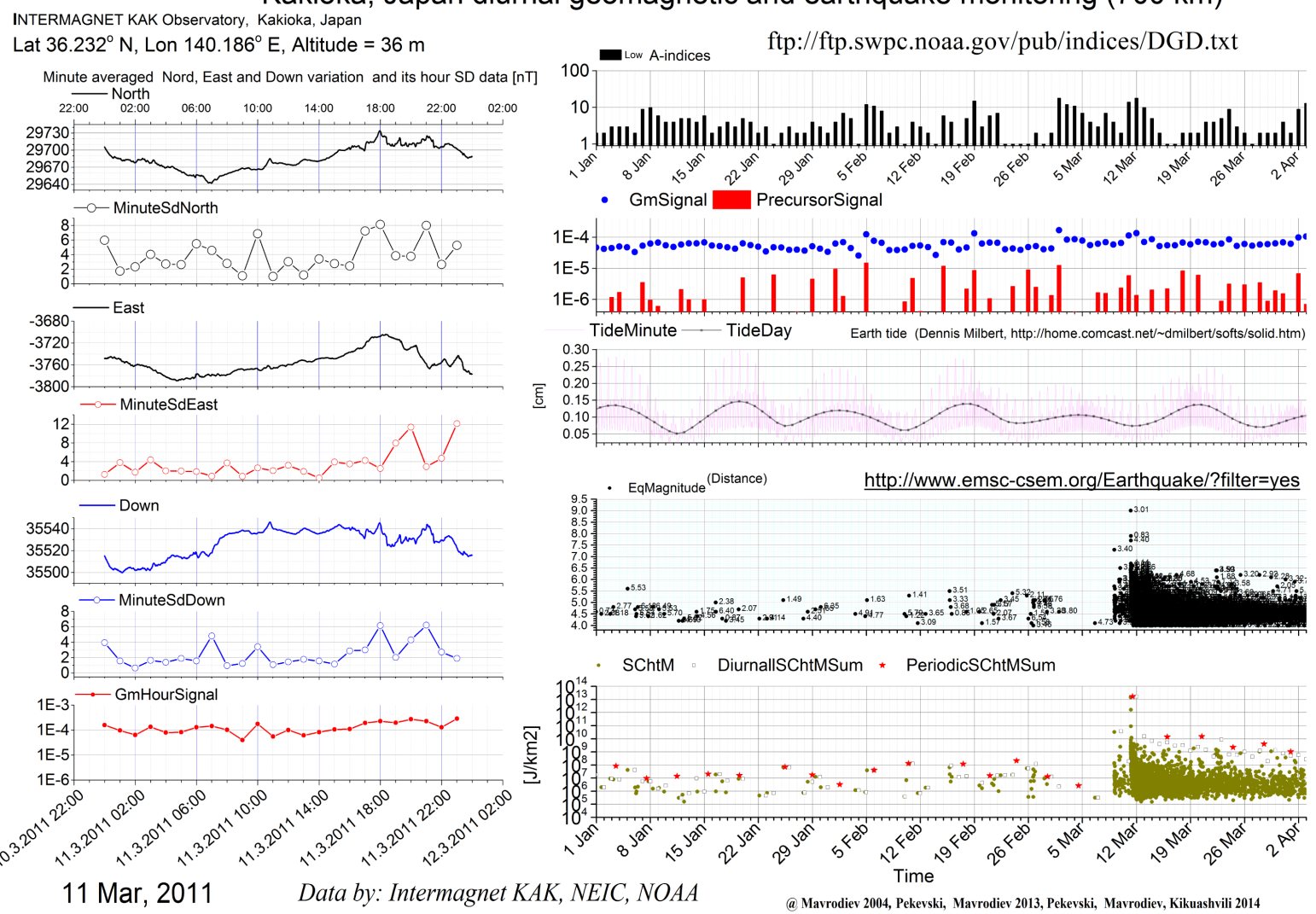

Figure 1. Kakioka diurnal geomagnetic and earthquakes monitoring in the time period around the Fukushima earthquake with geomagnetic field on 11 March 2011. 
- The software for calculation of the daily and minute Earth tide behaviour [40] (Dennis Milbert, NASA);

- The Earth tide extremes (daily average maximum, minimum and inflexed point) as a trigger of earthquakes;

- The data for World A-indices, www.swpc.noaa.gov.

The geomagnetic signal is calculated as a simple function of relative standard deviations of the components of the geomagnetic vector. The precursor signal is the difference between today and yesterday's geomagnetic signal corrected by the A- indices values. As the increase of precursor signal means increase of geomagnetic field variability, we call such positive leap a geomagnetic quake in analogy with an earthquake. The analysis of the correlation between the earthquakes occurred and the time of Sun- Moon Earth tide extremes on the basis of the variable earthquake's surface energy density $\boldsymbol{S}_{\text {Cht } M}$ permits to forecast the imminent regional seismic activity. The calculation of the day differences (DayDiff) between the time of the earthquakes occurred and the time of the nearest Tide extreme permits to build the curve of DayDiff and its Gauss fit. The comparison of Gauss widths for all the earthquakes occurred and those with the biggest $\boldsymbol{S}_{\boldsymbol{C h t M}}$ is basis for formulation the hypothesis for "predictable" earthquakes.

\subsection{The Simple Mathematics and Description of Variables}

The simple mathematics for the calculation of the precursor signal, the software for illustrating the reliability of forecasting and its statistic estimation and the variables in Figure 1 are described as follows.

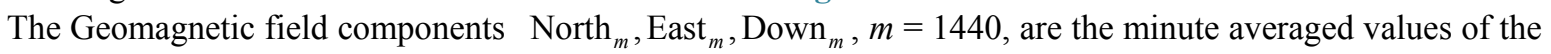
geomagnetic vector $F$, and the variables $S d$ North $_{h}, S d$ East $_{h}, S d$ Down $_{h}$ are their standard deviation, calculated for 1 hour, $h=1, \cdots, 24)$ :

$$
S d \text { North }_{h}=\sqrt{\frac{\sum_{m=1}^{60}\left(\overline{\text { North }_{h}}-\text { North }_{m}\right)^{2}}{60}}
$$

where

$$
\overline{\text { North }_{h}}=\frac{\sum_{m=1}^{60} \text { North }_{m}}{60}
$$

The geomagnetic signal GeomHourSig ${ }_{h}$ is the geometrical sum of hour standard deviation normed by the module of hour geomagnetic vector:

$$
\text { GeomHourSig }=\sqrt{\frac{S d \text { North }_{h}^{2}+S d \text { East }_{h}^{2}+S d \text { Down }_{h}^{2}}{{\text { North }_{h}}^{2}+{\overline{\text { East }_{h}}}^{2}+{\overline{\text { Down }_{h}}}^{2}}}
$$

The $\boldsymbol{A}$ indices are the Low, Medium and High indices, calculated by the NOAA, Space weather prediction center: www.swpc.noaa.gov. In this paper we use $A_{\text {low }}$;

The variable $\mathrm{GmSig}_{\text {day }}$ is the diurnal mean value of $\mathrm{GmHourSig}_{h}$ :

$$
\text { GeomSig }_{\text {day }}=\frac{\sum_{h=1}^{24} \text { Geom }_{\text {HourSig }}}{24}
$$

and PrecursorSig day

$$
\text { PrecursorSig } g_{\text {day }}=2 \frac{\text { Geom } \mathrm{Si}_{\mathrm{day}}-\text { GeomSig }_{\text {yesterday }}}{A l o w_{\text {day }}+\text { Alow }_{\text {yesterday }}}
$$

The indices of earthquake's magnitude value are the distance in hundred km between the epicenter and the monitoring point.

The variable $S_{C h t M}$ is the modified earthquake's surface energy flow density in the monitoring point:

$$
S_{C h t M}=\frac{10^{(1.4 M a g+4.8)}}{(40+\text { Depth }+ \text { Distance })^{2}}\left[\mathrm{~J} / \mathrm{km}^{2}\right]
$$


The variable Periodic $S_{C h t M}$ Sum $\left[\mathrm{J} / \mathrm{km}^{2}\right]$ is the sum of the variable $S_{C h t M}$ for all earthquakes occurred in the time period $+/-2.7$ days before and after the tide extreme in the $700 \mathrm{~km}$ region around the monitoring point. Obviously, its value can serve as estimation of the regional seismic activities for the time period around the tide's extreme.

The variable Diurnal $S_{C h t M}$ Sum $\left[\mathrm{J} / \mathrm{km}^{2}\right.$ per day $]$ is the sum of the variable $S_{C h t M}$, calculated for all earthquakes occurred during the day in the $700 \mathrm{~km}$ region around the monitoring point. This variable can serve as a quantitative measure of diurnal regional seismicity.

One has to note that the explicit form of the variable $S_{C h t M}$ was established in the framework of inverse problem [41] [42] with the condition to have a clearer correlation between the variable PrecursorSig day and Periodic $S_{C h t M}$ Sum .

The variable Tide Minute $[\mathrm{cm}]$ is the module of tide vector calculated every 15 minutes;

The variable Tide Day $[\mathrm{cm}]$ is the diurnal mean value in time calculated in the analogy of mass center formulae in many bodies' classical mechanics:

$$
\text { Time }_{\text {TideDay }}=\frac{\sum_{m=1}^{360} m \text { TideDay }_{m}}{\sum_{m=1}^{360} \text { TideDay }_{m}}
$$

Note: For seconds and more samples per second, the generalization has to calculate geomagnetic field characteristics for every minute and correspondingly the values of $\mathrm{GmSig}_{\text {day }}$ have to be the average for $1440 \mathrm{~min}$ utes.

The positive value of the variable PrecursorSig day means that the geomagnetic field variability, which is calculated via standard deviations of geomagnetic fileld components, is increasing. In analogy with earthquake we call such increase a geomagnetic quake.

As one can see from Figure 1, after the appearance of a geomagnetic quake, in nine of twelve cases (75\%), the regional seismic activity is increasing (the bigger value of the Periodic $S_{C h t M}$ Sum variable) in the time period aroundthe followingtide extreme. So, the geomagneticquake approach described can serve as a forecast of imminent regional seismic activity.

In Figure 1 the values of the variable Periodic $S_{C h t M}$ Sum are calculated not only in the time periods around the extremes, but also in the time period between them. We can see that its values in almost every extreme period are higher.

The use of the above described analysis for a longer time period with calculation of distribution of day difference between the "predicted" earthquakes (earthquakes with the highest value $S_{C h t M}$ ) can demonstrate the reliability of the approach for forecasting imminent regional seismic activity for regions with seismic risk.

\section{Reliability of Geomagnetic Quake Approach Based on the Analyses of INTERMAGNET Data from MMB (Memambetsu), KAK (Kakioka) and KNY (Kanoya) Stations Located in Japan (Figures 2-12)}

In the following Table 1 we present the sum of the variable $S_{C h t M}$ for all earthquakes occurred in the station's region $(700 \mathrm{~km})$ and the sum of $S_{C h t M}$ for predicted one, their division in persent and the widths of DayDiff distribution Gauss fitfor all earhquakes, including the ones predicted.

The values of divisions near to $100 \%$ for all the three stations confirm the reliability of the imminent regional seismic activity forecasting. The values of Gauss fit widths can be interpreted as a confirmation of our hypotesis about "predicted" earthquakes: the stronger the earthquake is, the higher is the probability that after the precursor signal it will occur in the region in the time period (+/- 1.97 days) around the time of the following Tide's extreme.

Table 1. Illustration of reliability.

\begin{tabular}{cccccc}
\hline Station & PrEqs $\mathrm{S}_{\mathrm{ChtM}} \operatorname{Sum}\left[\mathrm{J} / \mathrm{km}^{2}\right]$ & AllEqs $\mathrm{S}_{\mathrm{ChtM}} \operatorname{Sum}\left[\mathrm{J} / \mathrm{km}^{2}\right]$ & $\operatorname{Pr} /$ All \% & Gauss fit width all [day] & Gauss fit width PrEqs [day] \\
\hline $\mathrm{MMB}$ & $4.01 \mathrm{E}+12$ & $4.11 \mathrm{E}+12$ & 97.6 & $5.14+/-0.56$ & $4.32+/-0.72$ \\
$\mathrm{KAK}$ & $1.48 \mathrm{E}+13$ & $1.68 \mathrm{E}+13$ & 88.1 & $4.89+/-0.60$ & $3.75+/-0.37$ \\
$\mathrm{KNY}$ & $1.96 \mathrm{E}+10$ & $1.98 \mathrm{E}+10$ & 99.0 & $5.44+/-0.0$ & $3.74+/-0.51$ \\
\hline
\end{tabular}


Memambetsu, Japan diurnal geomagnetic and earthquake monitoring (700 km)

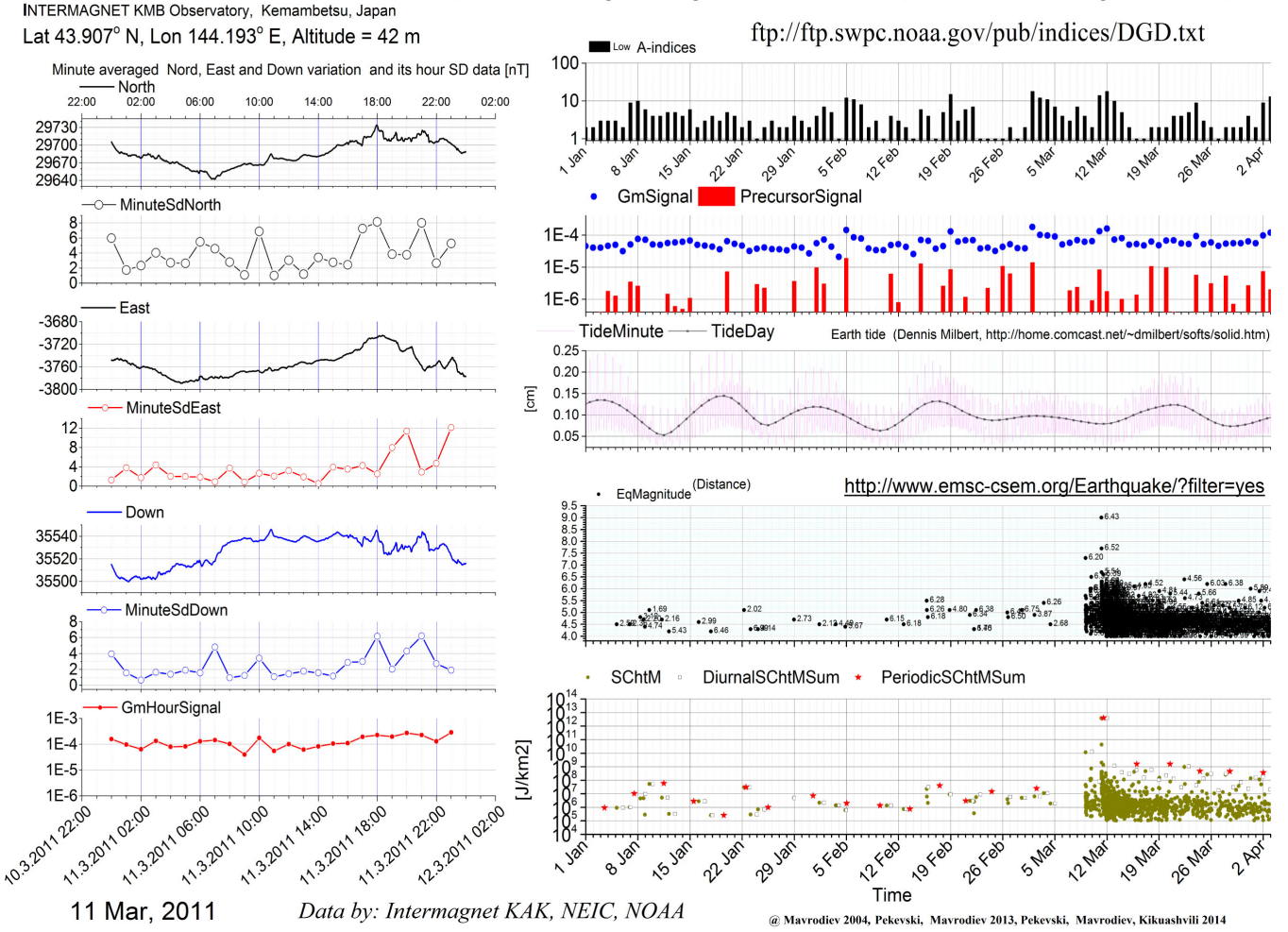

Figure 2. The Memambetsu diurnal geomagnetic and earthquakes monitoringin the period around the time of the Fukushima earthquake with geomagnetic field on 11 March 2011.

Memambetsu, Japan diurnal geomagnetic and earthquake monitoring (700 km)

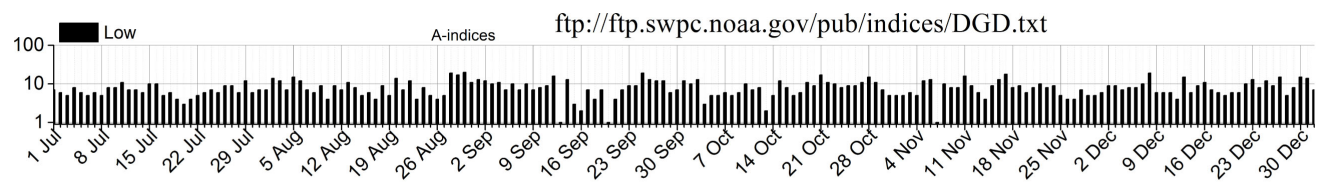

- GmSignal PrecursorSignal
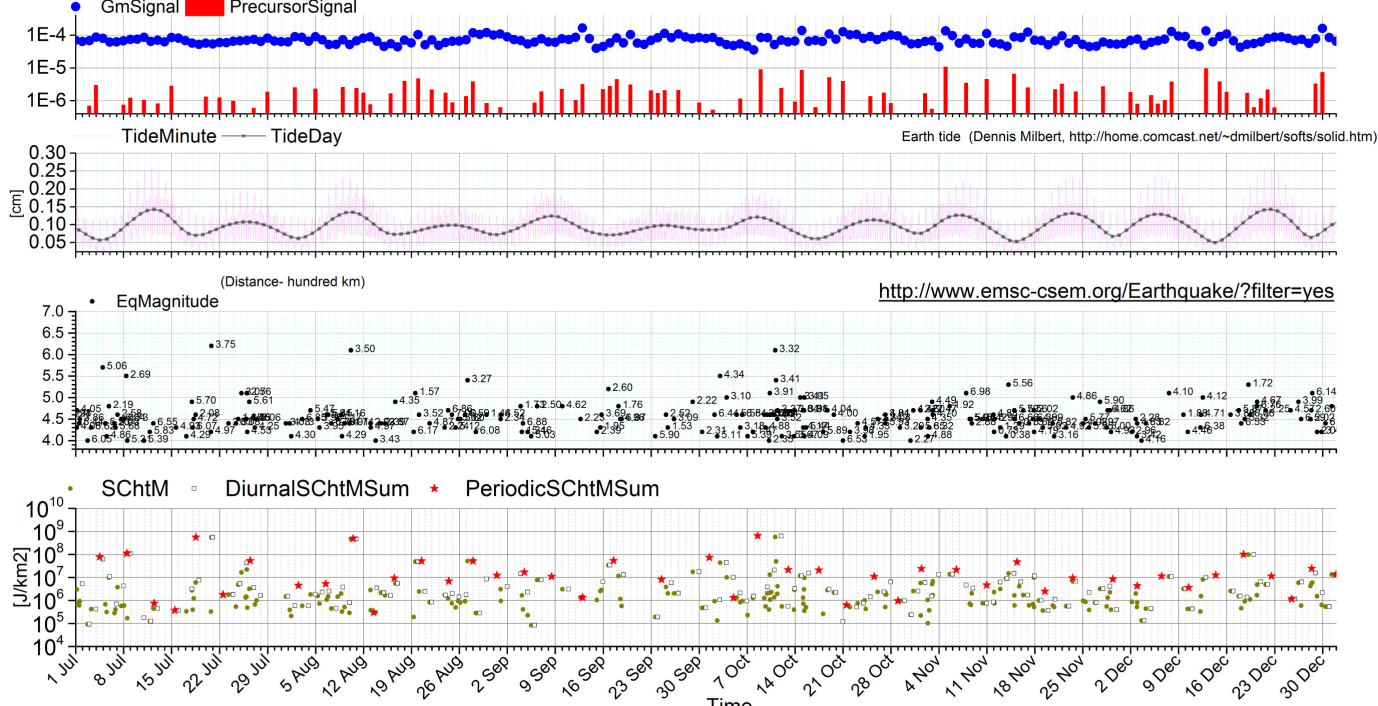

$31 \mathrm{Dec}, 2014$

Data by: Intermagnet KAK, NEIC, NOAA

Figure 3. Memambetsu diurnal geomagnetic and earthquakes monitoring for the period 1 July 2014-1 January 2015. 


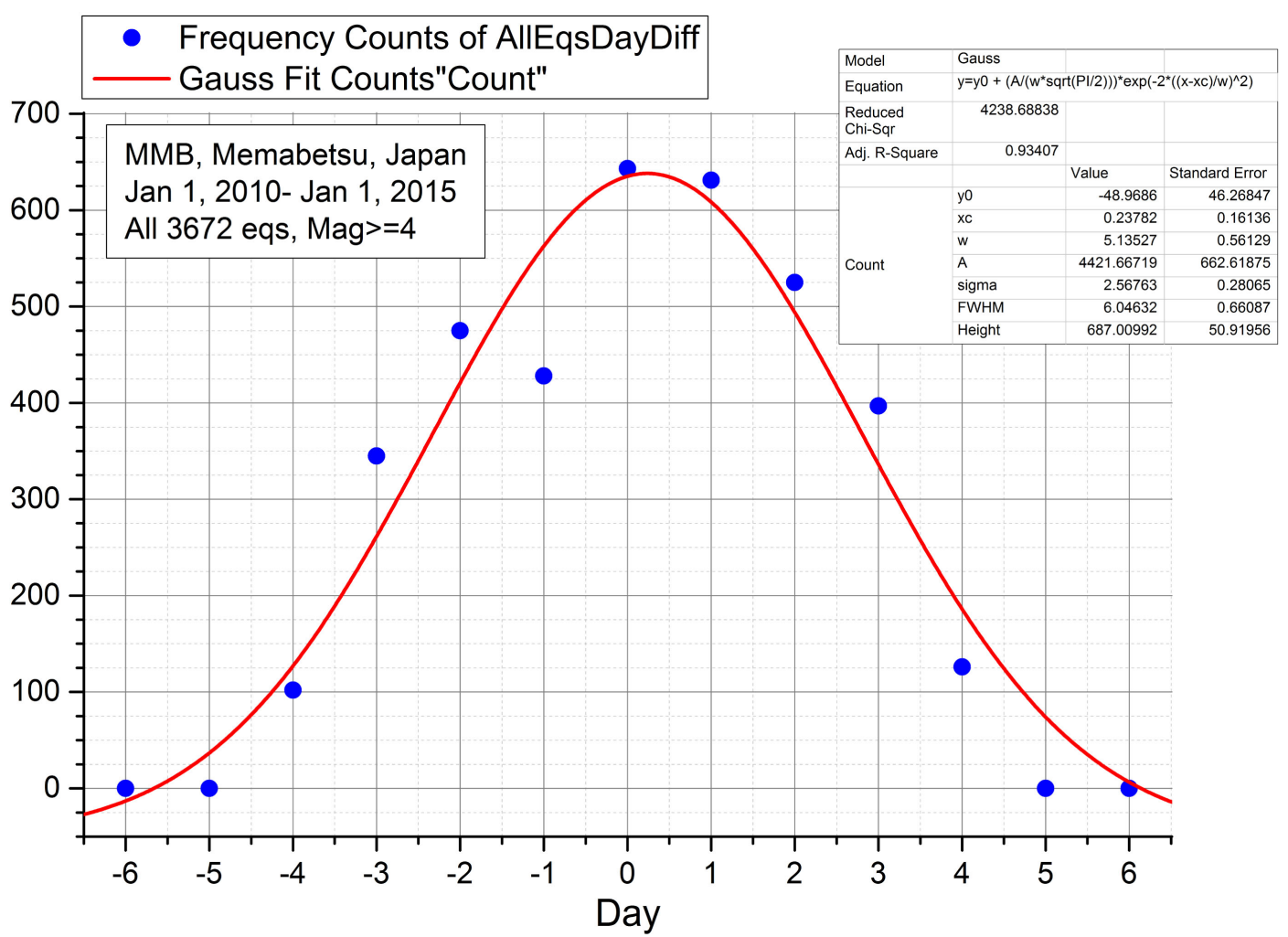

Figure 4. The distribution and its Gauss fit of DayDiff for all earthquakes occurred in Memambetsu (700 km) region.

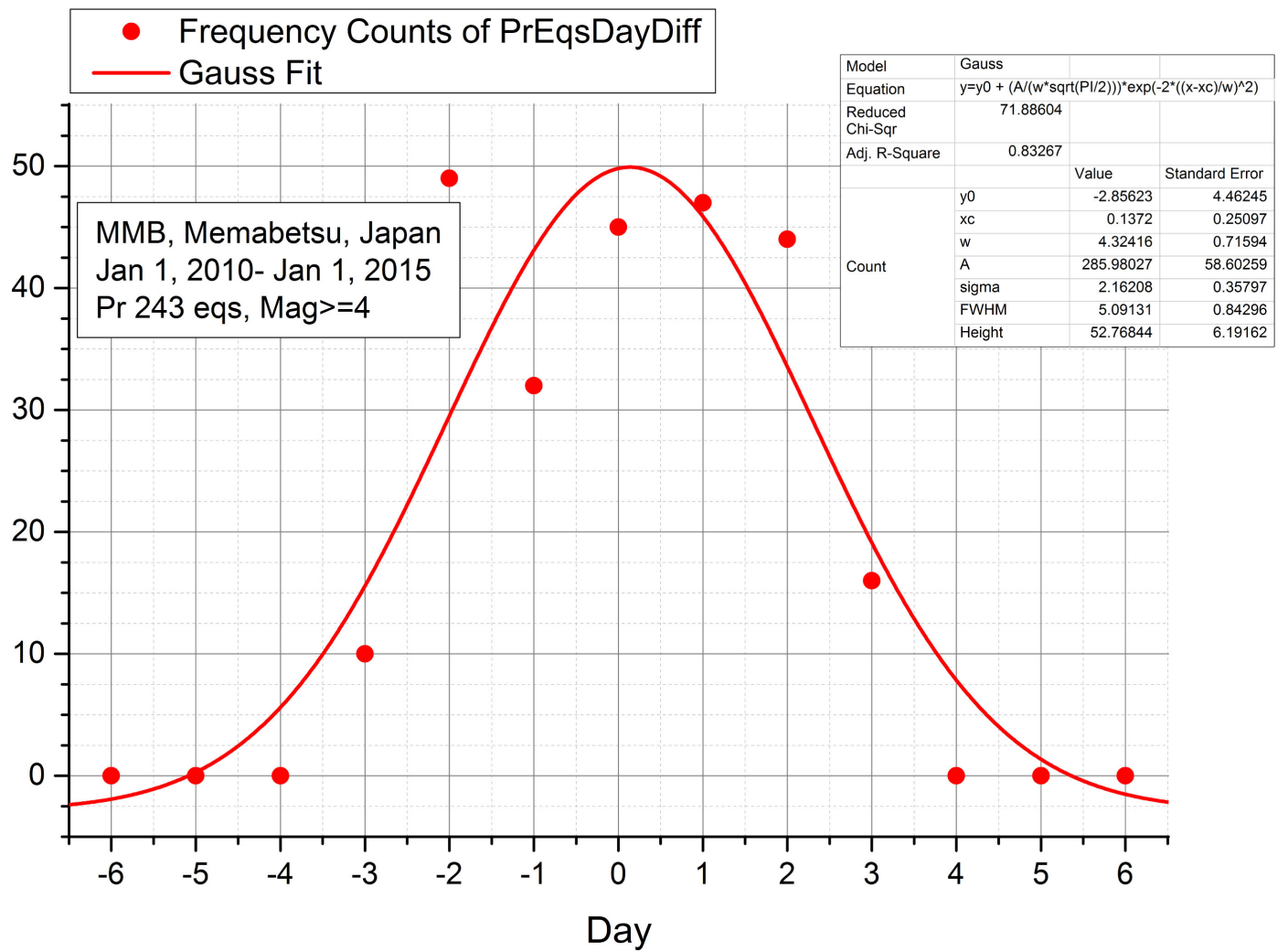

Figure 5. The distribution and its Gauss fit of DayDiff for predicted earthquakes in Memambetsu (700 km) region. 
Kakioka, Japan diurnal geomagnetic and earthquake monitoring (700 km)

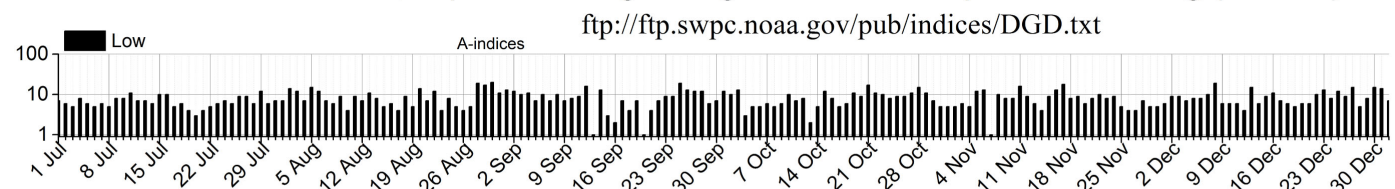

- GmSignal PrecursorSignal
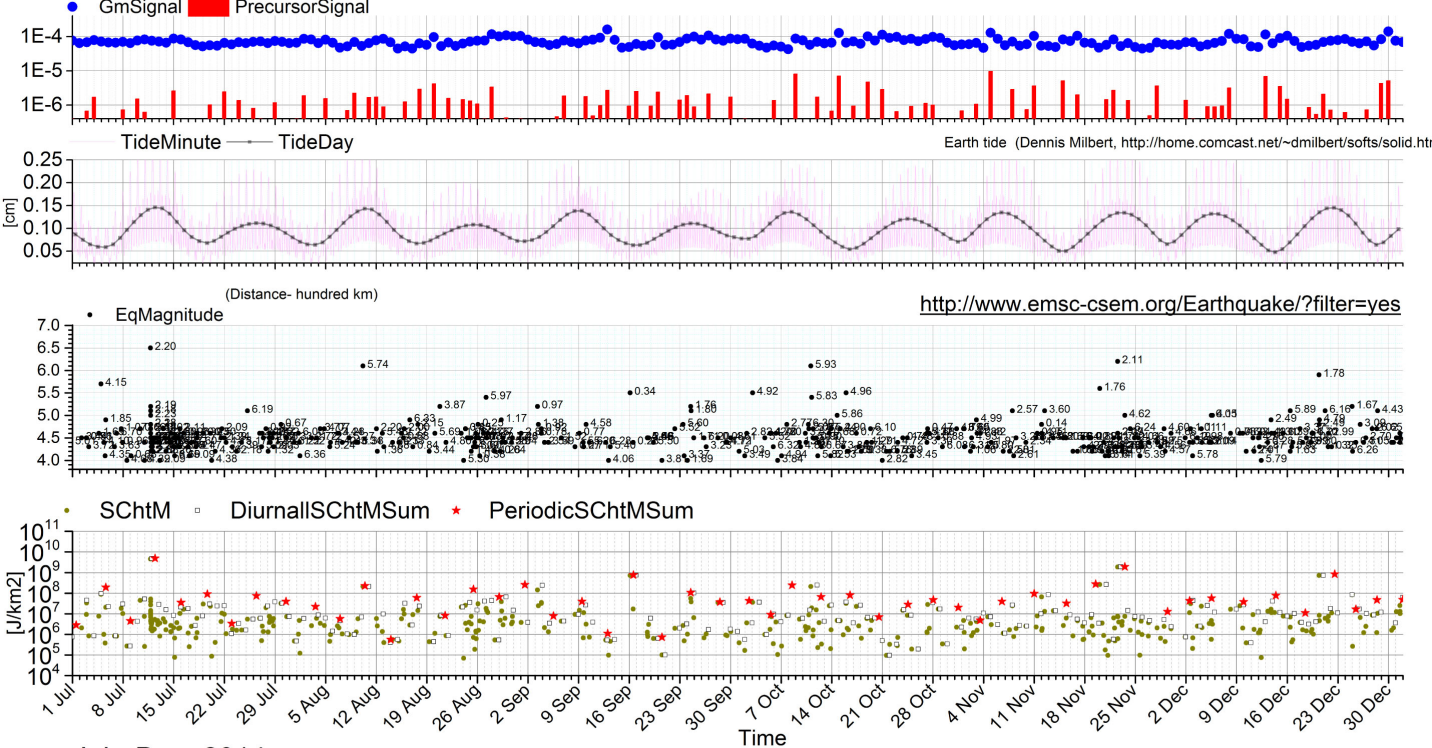

Jul - Dec, 2014 Data by: Intermagnet KAK, NEIC, NOAA

(a) Mavrodiev 2004, Pekevski, Mavrodiev 2013, Pekevski, Mavrodiev, Kikuashvili 2014

Figure 6. Kakioka diurnal geomagnetic and earthquakes monitoring for the period 1 July 2014-1 January 2015.

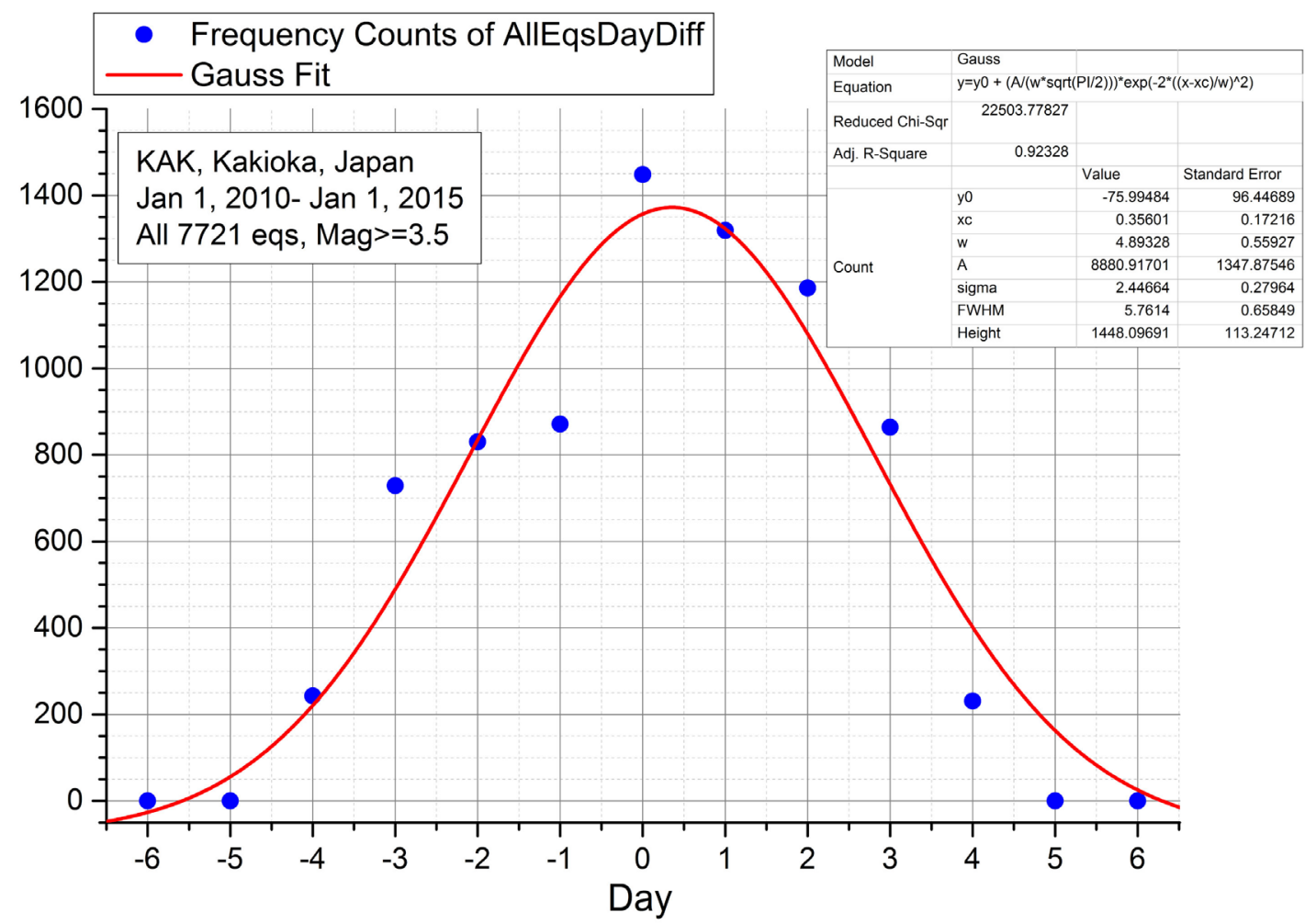

Figure 7. The distribution and its Gauss fit of DayDiff for all earthquakes occurred in Kakioka (700 km) region. 


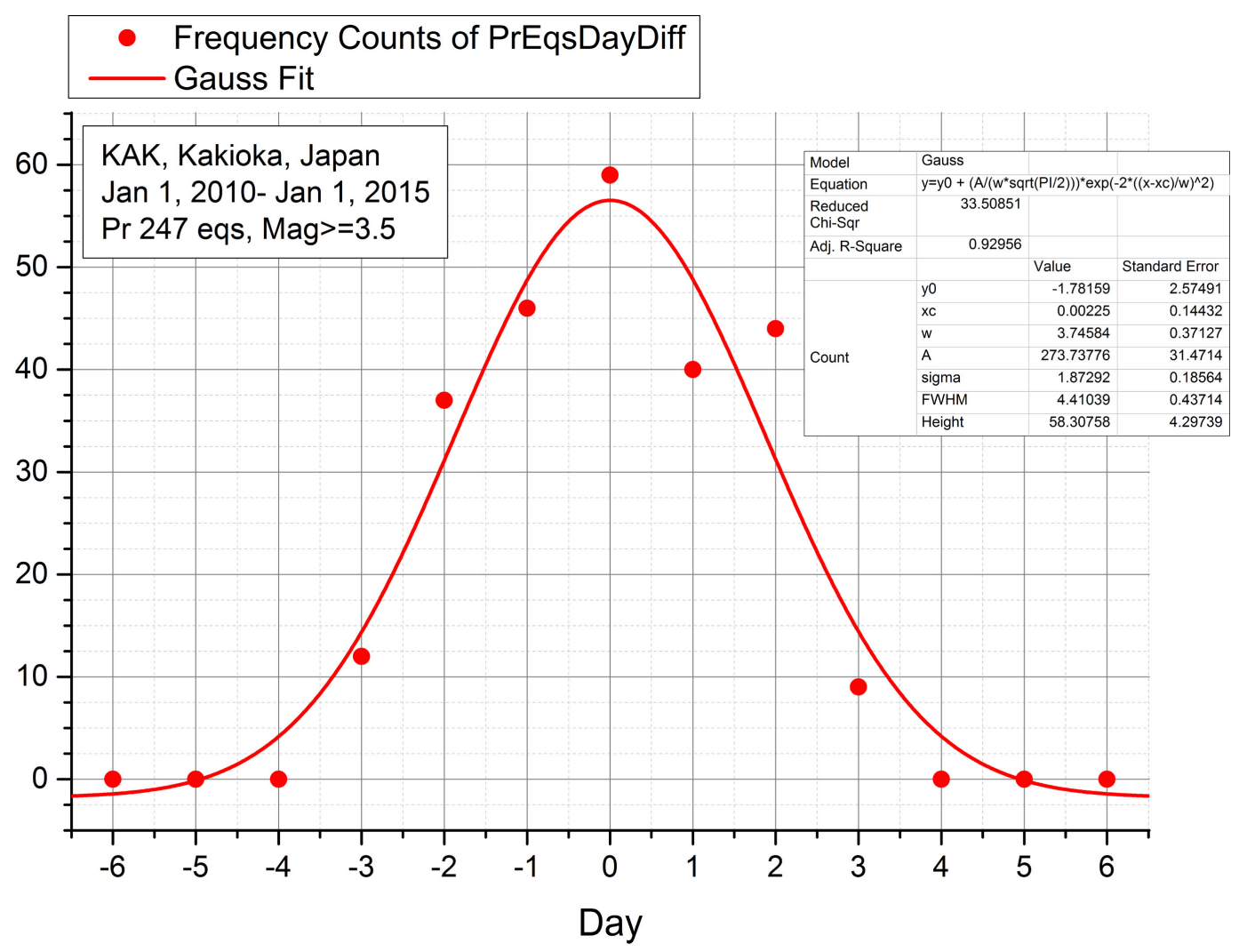

Figure 8. The distribution and its Gauss fit of DayDiff for predicted earthquakes in Kakioka $(700 \mathrm{~km})$ region.

Kanoya, Japan diurnal geomagnetic and earthquake monitoring (700 km)

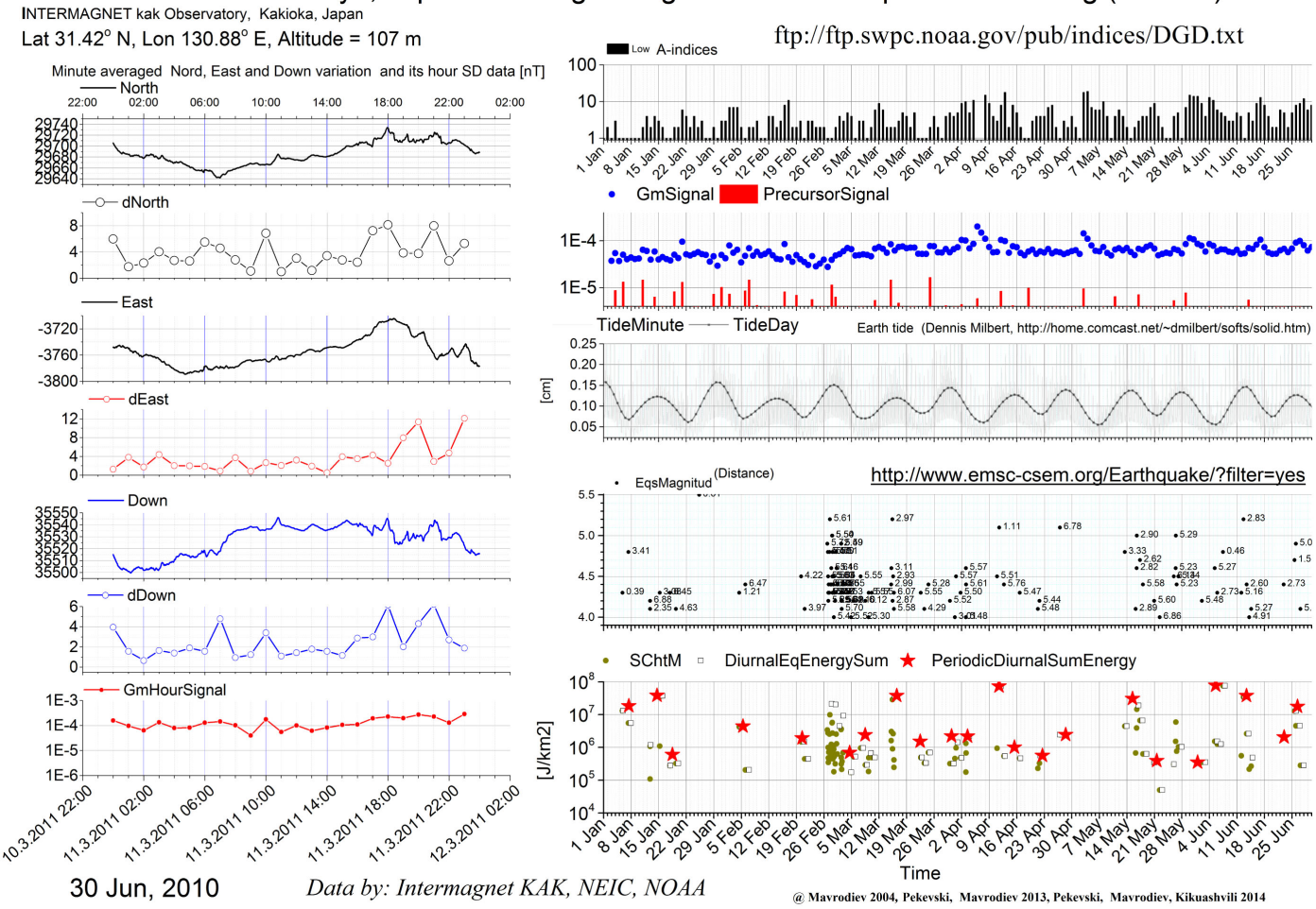

Figure 9. Kanoya diurnal geomagnetic and earthquakes monitoring with geomagnetic field on 30 June 2010. 
Kanoya, Japan diurnal geomagnetic and earthquake monitoring (700 km)
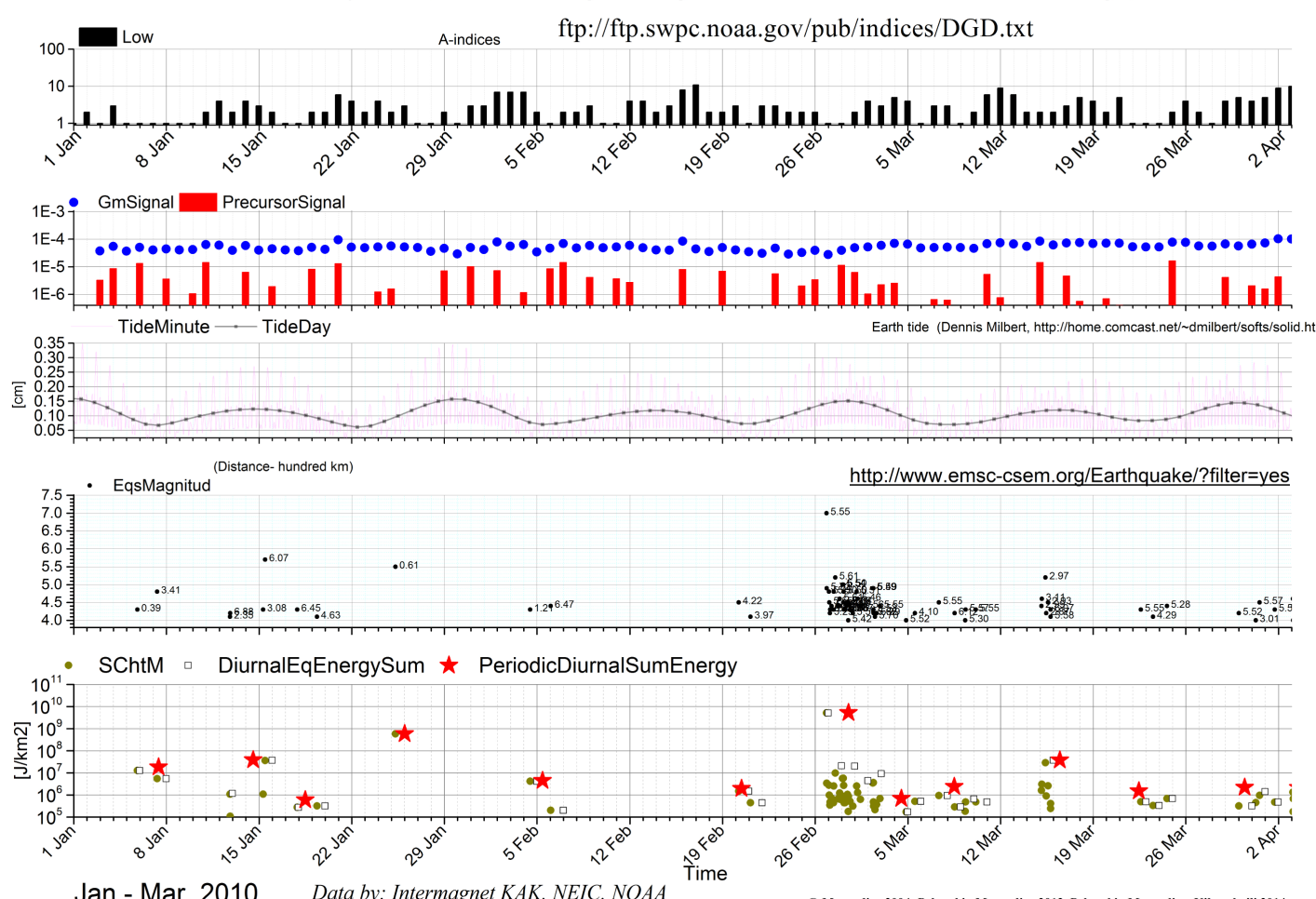

Figure 10. Kanoya diurnal geomagnetic and earthquakes monitoring with geomagnetic field in the period Jan-Mar, 2010.

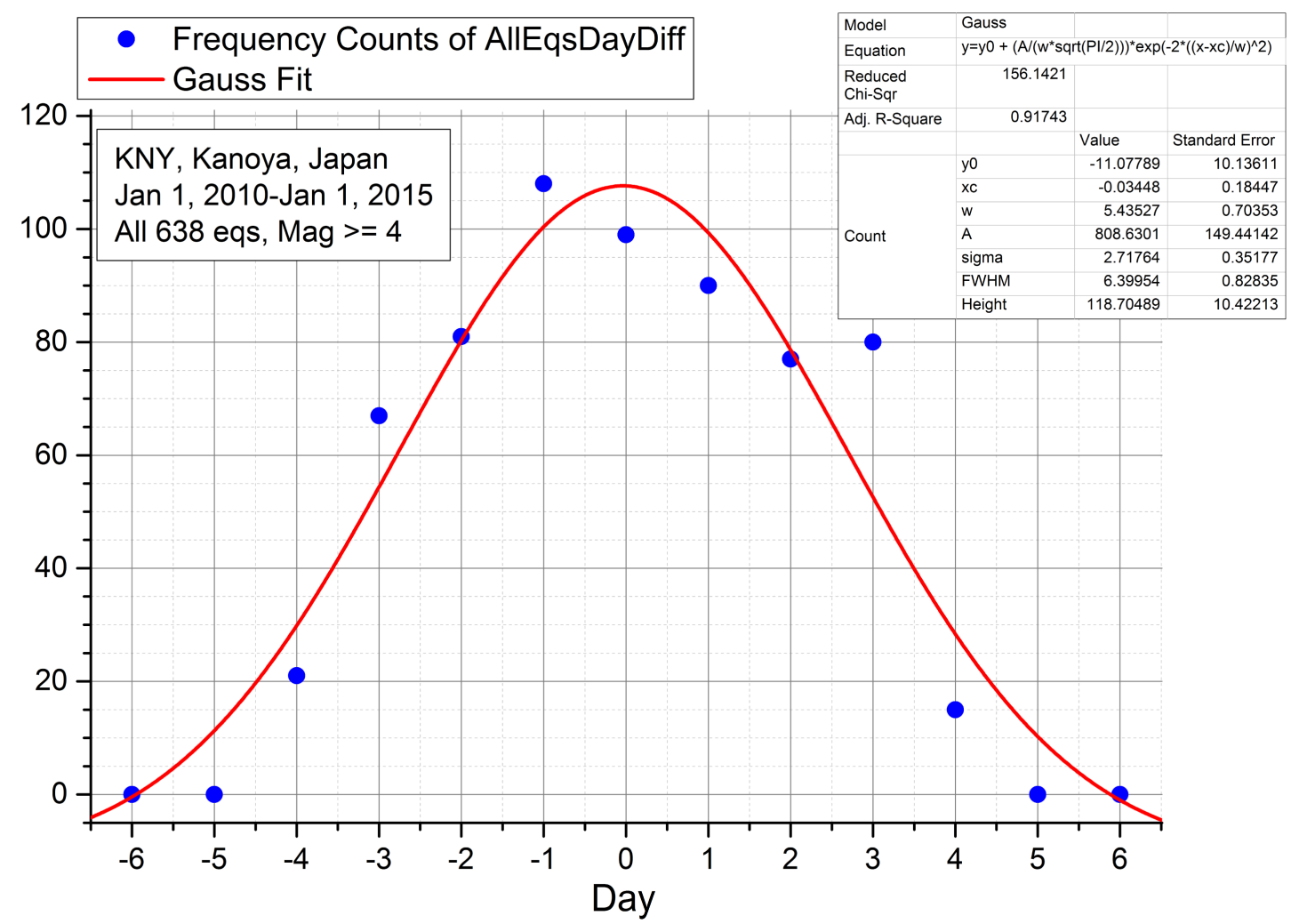

Figure 11. The distribution and its Gauss fit of DayDiff for all earthquakes occurred in Kanoya (700 km) region. 


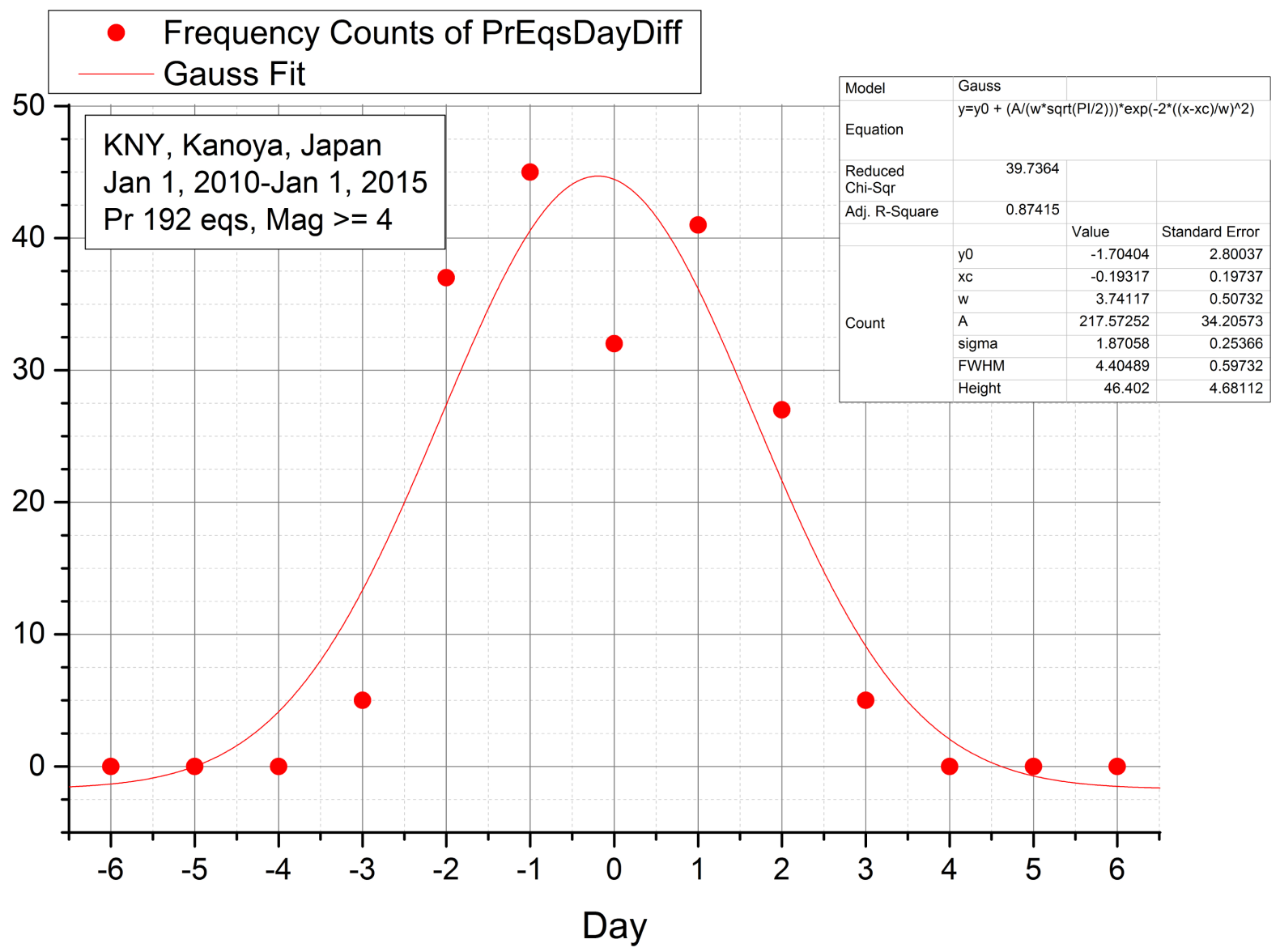

Figure 12. The distribution and its Gauss fit of DayDiff for the earthquakes predicted in Kanoya (700 km) region.

\section{Description of Precursor Signal as a Function of Earthquake’s Magnitude, Depth and Distance}

Upon analysing the data for predicted earthquakes presented in Figure 5, Figure 8 and Figure 12, it was established that there are sixteen earthquakes which are predicted from the signal in two stations simultaneously (see Table 2 in Application 1). So, we have 32 equations for precursor signals, earthquake's magnitude and depth as well as for the distances between the epicenters of the earthquakes occurred and the monitoring points, in which 16 magnitudes and depths have equal values. In this way we have enough data to formulate the inverse problem —-solving the overdetemined system:

$$
\text { PrecursorSig }_{i}^{\text {Expt }}=\operatorname{Th}\left(\mathrm{Mag}_{i}, \text { Depth }_{i}, R_{i}, A\right)
$$

where $i=1, \cdots, 32$, the distance between the epicenter $x_{i}, y_{i}$ and the corresponding monitoring point $x_{0}, y_{0}$ is $R_{i}=R\left(x_{i}, y_{i}, x_{0}, y_{0}\right)$ and $A\left(a_{i}, i=1, \cdots, n\right)$ is a set of unknown digital parameters which define the behaviour of the explicit form of function $T h\left(\operatorname{Mag}_{i}, \operatorname{Depth}_{i}, R_{i}, A\right)$. The discovery of its explicit form and the values of parameter was performed with program code REGN [41]-[45] and its Fortran version is presented in Applica-

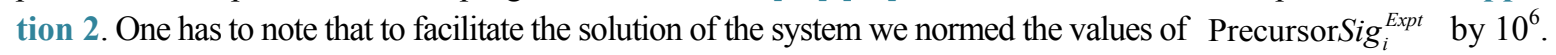

The accuracy of description of the experimet is presented in the following Figure 13 by variable Res :

$$
\operatorname{Res}_{i}=\left(\text { PrecursorSig }_{i}^{\text {Expt }}-\operatorname{Th}\left(\operatorname{Mag}_{i}, \text { Depth }_{i}, R_{i}, A\right)\right) / \text { PrecursorSig }_{i}^{\text {Expt }}
$$

where $i=1, \cdots, 32$, (Figure 14 is the map illustration of Figure 13). 


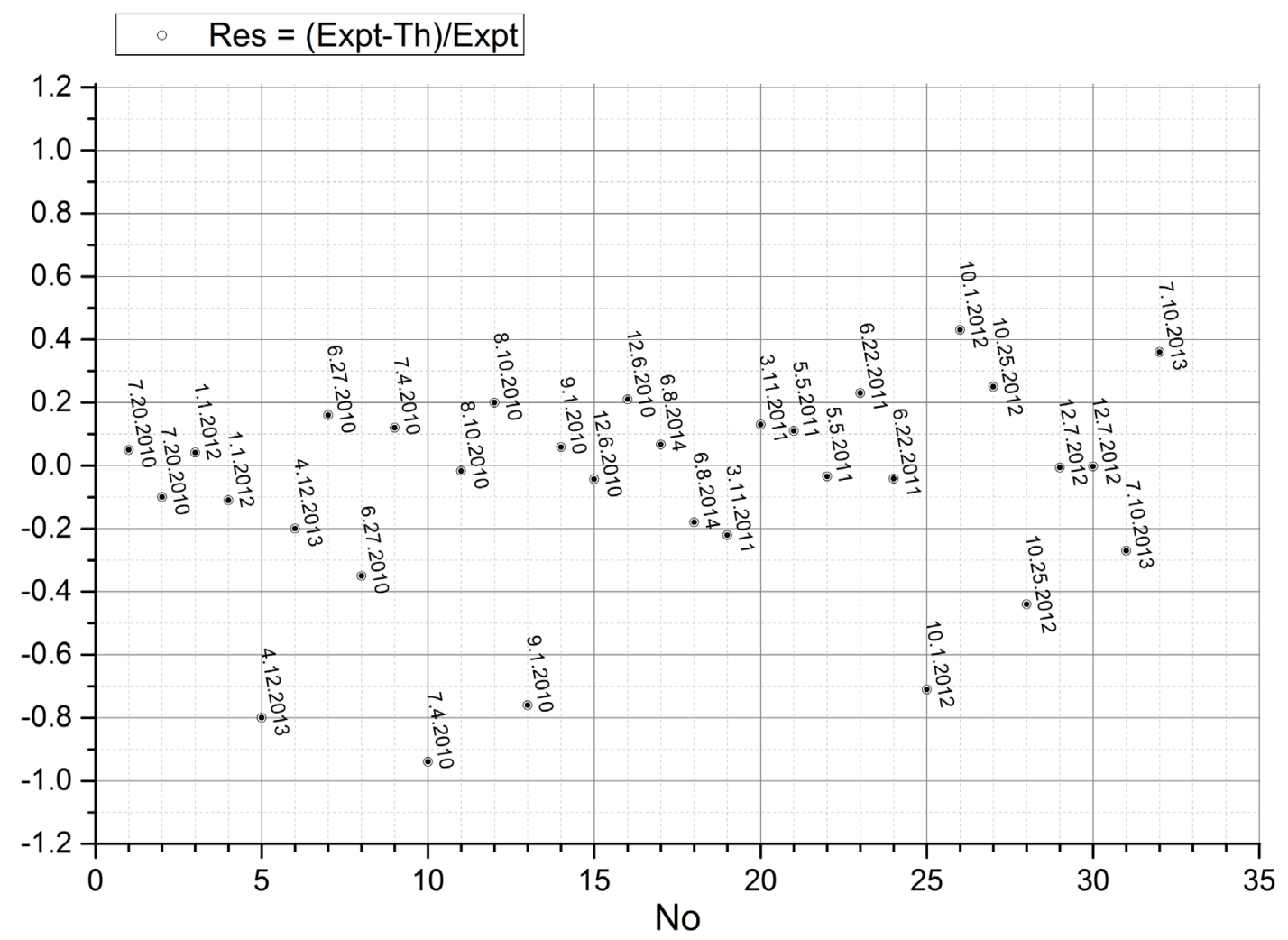

Figure 13. The description of precursor signal as afunction of earthquake's magnitude, depth and distance.

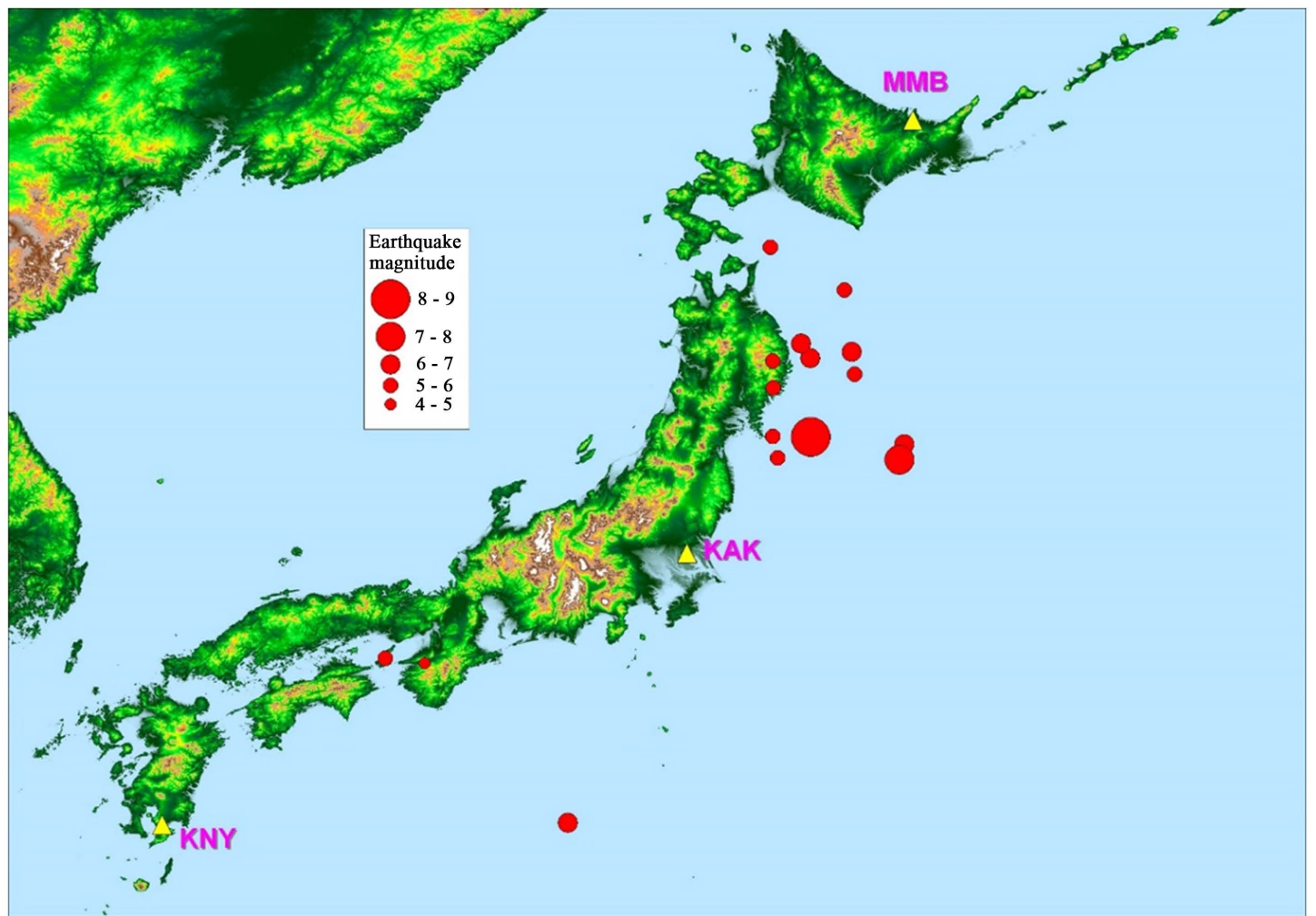

Figure 14. The map illustration of Figure 13. 


\section{Formulation of Inverse Problem for Regional Imminent Forecasting the Magnitude, Depth and Epicenter Coordinates of Earthquake}

In this section we will present apossibility for solving the inverse problem for the parameters established for an incoming earthquake - the time period, magnitude, depth and epicenter coordinate.

If our hypotesis for predicted earthquake is true, itmeans that after a geomagnetic quake in the following tide extreme with anaccuracy equal to $+/-2$ days al leas one earthquake in the region will occur.

From the previous section we know the explicit form of precursor signal depending on the magnitude, depth and coordinates of the epicenter- 4 variables. It means that the number of unkonwn parameters $\mathrm{N}$ is

$$
N=2+2 \cdot G
$$

where $\boldsymbol{G}$ is the number of geomagnetic monitoring points.

But the number of equations is $G$, which means that with a Network for only one precursor it is not possible to solve the problem for calculation of Mag, Depth and Coordinates of an incoming earthquake.

The condition to have sufficient data for defining the overdetemined system of equations is:

$$
2+2 \cdot G \leq P \cdot G
$$

where $\boldsymbol{P}$ is the number of precursors (Earth Geomagnetic field, Earth currents field, Borehole water level, Radon concentration, Soil temperature, Atmosphere and Earth core low frequency waves, Ionosphere variability).

which has a solution if $P \geq 3$ at $G>2$.

In case this condition is respected, the first stage of research allows to estimate the epicenter coordinates using simple triangulation, the condition (9) is

$$
2+G \leq P \cdot G
$$

with solution $\boldsymbol{P}>2$ and $\boldsymbol{G}>=2$.

Of course, one has to note that the proposed scheme will take place after the reliability test of earthquake's precursors (mentioned in many papers) as Earth electric current, borehole water level, radon concentration, soil temperature, ionosphere behaviour, low frequences wave in the atmosphere and the Earth core will be performed.

\section{Conclusions}

The approach proposed for solving the problem of regional imminent "how, where and when" earthquake's prediction does not except the commonly accepted investigations based on seismology, geology, geoelectromagnetism and JPS data.

The reliability test of the Earth currents, Borehole water level, Radon concentration, Atmosphere and the terrestrial low frequency waves as demonstrated in this paper geomagnetic quake reliability for forerecasting the regional seismic activity, after including them in a regional network, will give data for discovering the explicit forms of different precursor signal functions. After collecting enough statistics for a suffucient number of earhquakes occurred in the network region and solving the overdetermined systems defined from conditions (9) or (10), we will have data for estimating the prediction accuracy for earthquake's time period, magnitude, depth and epifocal coordinates prediction accuracy.

\section{Acknowledgements}

I would like to thank my co-authors from BlackSeaHazNet FP7 IRSES (2011-2014) for cooperation and discussions, Boris Vasilev, JINR, Dubna for the one-component magnetometer, the mathematician and programmer Lubomir Aleksandrov for his code REGN and discussions on the inverse problem methods, Oleg Molchanov and Alexey Sissakyan for many years of fruitful polemics, as well as my late Professor Vladimir Kadyshevsky, who taught me how to try to gradually understand the physics with analyzing the dynamics and kinemathics of the processes in different time, space and energy scales.

Special thanks to Lazo Pekevski, Ludwig Ries, Alexandr Vol and Arie Gilat for the help in the preparation of the paper.

\section{References}

[1] Main, I. (1999) Is the Reliable Prediction of Individual Earthquakes a Realistic Scientific Goal? Nature Debates. 
http://www.nature.com/ nature/ /earthquake/quake contents.html

[2] Main, I. (1999) Earthquake Prediction: Concluding Remarks. Nature Debates, Week 7.

[3] Ludwin, R.S. (2001) Earthquake Prediction. Washington Geology, 28, 27-28.

[4] Pakiser, L. and Shedlock, K.M. (1995) Predicting Earthquakes. USGS, Reston, US. http://earthquake.usgs.gov/hazards/prediction.html

[5] Geller, R.J., Jackson, D.D., Kagan, Y.Y. and Mulargia, F. (1997) Earthquakes Cannot Be Predicted. Science, 275, 1616-1617. http://scec.ess.ucla.edu/ $\%$ 7Eykagan/perspective.html

[6] Tamrazian, G.P. (1967) Tide-Forming Forces and Earthquakes. International Journal of Solar Energy (Ikarus), 7, 5965.

[7] Knopoff, L. (1964) Earth Tides as a Triggering Mechanism for Earthquakes. Bulletin of the Seismological Society of America, 54, 1865-1870.

[8] Ryabl, A., Van Wormer, J.D. and Jones, A.E. (1968) Triggering of Micro-Earthquakes by Earth Tides and Other Features of the Truckee, California, Earthquakes Sequence of September 1966. Bulletin of the Seismological Society of America, 58, 215-248.

[9] Shlien, S. (1972) Earthquake-Tide Correlation. Geophysical Journal International, 28, 27-34. http://dx.doi.org/10.1111/j.1365-246X.1972.tb06108.x

[10] Molher, A.S. (1980) Earthquake/Earth Tide Correlation and Other Features of the Susanville, California, Earthquake Sequence of June-July 1976. Bulletin of the Seismological Society of America, 70, 1583-1593.

[11] Sounau, M., Sounau, A. and Gagnepain, J. (1982) Modeling and Detecting Interaction between Earth Tides and Earthquakes with Application to an Aftershock Sequence in the Pyrenees. Bulletin of the Seismological Society of America, 72, 165-180.

[12] Shirley, J. (1988) Lunar and Solar Periodicities of Large Earthquakes: Southern California and the Alaska Aleutian Islands Seismic Region. Geophysical Journal International, 92, 403-420.

[13] Bragin, Y.A., Bragin, O.A. and Bragin, V.Y. (1999) Reliability of Forecast and Lunar Hypothesis of Earthquakes. The 22nd General Assembly of the International Union of Geodesy and Geophysics (IUGG), Birmingham, 18-30 July 1999.

[14] Pulinets, S.A., Ouzounov, D.P., Karelin, A.V. and Davidenko, D.V. (1915) Physical Bases of the Generation of Short Term Earthquake Precursors: A Complex Model of Ionization-Induced Geophysical Processes in the LithosphereAtmosphere-Ionosphere-Magnetosphere System. Geomagnetism and Aeronomy, 55, 521-538.

[15] Contadakis, M., Biagi, P. and Zschau, J. (2002) Seismic Hazard Evaluation, Precursory Phenomena and Reliability of Prediction. Proceedings of the 27th EGS General Assembly, Nice, 21-26 April 2002. http://www.copernicus.org/EGS/EGS.html

[16] Papadopoulos, G. (2003) The 1st International Workshop on Earthquake Prediction Sub Commission on Earthquake Prediction Studies (SCE) of the European Seismological Commission Scheduled. Athens, Greece, November 2003. http://www.gein.noa.gr/ services/Workshop.htm

[17] Zhong, H.S. (1999) Earthquake Clouds and Short Term Prediction. http://quake.exit.com/

[18] Vartanyan, G.S. (2014) Fast Developing Deformational Cycles in the Lithosphere and Catastrophic Earthquakes:Was It Possible to Prevent the Fukushima Tragedy? Geophysical Processes and Biosphere, 13, 28-63.

[19] Sborshchikov, A., Kobzev, G., Mavrodiev, S. and Melikadze, G. (2013) Boreholes Water Level and Earthquake Prediction. BlackSeaHazNet Series, 3, 39.

[20] Ghosh, D., Deb, A. and Sengupta, R. (2009) Anomalous Radon Emission as Precursor of Earthquake. Journal of Applied Geophysics, 69, 67-81. http://dx.doi.org/10.1016/j.jappgeo.2009.06.001

[21] Gregoric, A., Zmazek, B., Kobal, I. and Vapotic, J. (2011) Radon as Earthquake Precursor. BlackSeaHazNet Series, 2, 175.

[22] Varotsos, P. and Alexopoulos, K. (1984) Physical Properties of the Variations in the Electric Field of the Earth Preceding Earthquakes I. Tectonophysics, 110, 93-98. http://dx.doi.org/10.1016/0040-1951(84)90059-3

[23] Varotsos, P. and Alexopoulos, K. (1984) Physical Properties of the Variations of the Electric Field of the Earth Preceding Earthquakes II. Tectonophysics, 110, 99-125. http://dx.doi.org/10.1016/0040-1951(84)90060-X

[24] Thanassoulas, C. (1991) Determination of the Epicentre Area of the Earthquakes (Ms > 6R) in Greece, Based on Electrotelluric Currents Recorded by the VAN Network. Acta Geophysica Polonica, 39, 373-387.

[25] Varotsos, P., Lazaridou, M., Eftaxias, K., Antonopoulos, G., Makris, J. and Kopanas, J. (1996) Short-Term Earthquake Prediction in Greece by Seismic Electric Signals. In: Ligthhill, S.J., Ed., A Critical Review of VAN: Earthquake Prediction from Seismic Electric Signals, World Scientific Publishing Cooperation, Singapore, 29-76.

http://dx.doi.org/10.1142/9789812815491_0002 
[26] Hayakawa, M. and Fujinawa, Y. (1994) Electromagnetic Phenomena Related to Earthquake Prediction. Terrapub, Tokyo, 677.

[27] Hayakawa, M., Fujinawa, Y., Evison, F.F., Shapiro, V.A., Varotsos, P., Fraser-Smith, A.C., Molchanov, O.A., Pokhotelov, O.A., Enomoto, Y. and Schloessin, H.H. (1994) What Is Future Direction of Investigation on Electromagnetic Phenomena Related to Earthquakes Prediction? In: Hayakawa, M. and Fujinawa, Y., Eds., Electromagnetic Phenomena Related to Earthquake Prediction, Terrapub, Tokyo, 667-677.

[28] Hayakawa, M. (1999) Atmospheric and Ionospheric Electromagnetic Phenomena Associated with Earthquakes. Terrapub, Tokyo, 996.

[29] Hayakawa, M., Ito, T. and Smirnova, N. (1999) Fractal Analysis of ULF Geomagnetic Data Associated with the Guam Earthquake on 8 August 1993. Geophysical Research Letters, 26, 2797-2800. http://dx.doi.org/10.1029/1999GL005367

[30] Mavrodiev, S. and Thanassoulas, C. (2001) Possible Correlation between Electromagnetic Earth Fields and Future Earthquakes. Seminar Proceedings of INRNE-BAS, Sofia, 23-27 July 2001. http://arXiv.org/abs/physics/0110012

[31] Hayakawa, M. and Molchanov, O. (2002) Seismo Electromagnetics Lithosphere-Atmosphere-Ionosphere Coupling. Terrapub, Tokyo, 477.

[32] Oike, K. and Yamada, T. (1994) Relationship between Shallow Earthquakes and Electromagnetic Noises in the LF and VLF Ranges. In: Hayakawa, M. and Fujinawa, Y., Eds., Electromagnetic Phenomena Related to Earthquake Prediction, Terrapub, Tokyo, 115-130.

[33] Saraev, A.K., Pertel, M.I. and Malkin, Z.M. (2002) Correction of the Electromagnetic Monitoring Data for Tidal Variations of Apparent Resistivity. Journal of Applied Geophysics, 49, 91-100. http://dx.doi.org/10.1016/S0926-9851(01)00101-X

[34] Eftaxias, K., Kapiris, P., Polygiannakis, J., Bogris, N., Kopanas, J., Antonopoulos, G., Peratzakis, A. and Hadjicontis, V. (2001) Signature of Pending Earthquake from Electromagnetic Anomalies. Geophysical Research Letters, 28, 3321-3324. http://dx.doi.org/10.1029/2001GL013124

[35] Eftaxias, K., Kapiris, P., Dologlou, E., Kopanas, J., Bogris, N., Antonopoulos, G., Peratzakis, A. and Hadjicontis, V. (2002) EM Anomalies before the Kozani Earthquake: A Study of Their Behaviour through Laboratory Experiments. Geophysical Research Letters, 29, 69-1-69-4. http://dx.doi.org/10.1029/2001gl013786

[36] Mavrodiev, S. (2004) On the Reliability of the Geomagnetic Quake as a Short Time Earthquake's Precursor for the Sofia Region. Natural Hazards and Earth System Sciences, 4, 433-447. http://dx.doi.org/10.5194/nhess-4-433-2004

[37] Mavrodiev, S., Pekevski, L. and Kikuashvili, G. (2013) Results of Black Sea Haz Net Project—FP7 IRSES Project: Extended Executive Summary, Conclusion Workshop. BlackSeaHazNet Series, 3.

[38] (2004) http://theo.inrne.bas.bg/ mavrodi/

[39] Kossobokov, V.G., Paresan, A. and Panza, G.F. (2015) On Operational Earthquake Forecast and Prediction Problems. Seismological Research Letters, 86, 287-290.

[40] NOAA. ftp://ftp.swpc.noaa.gov/pub/indices/DGD.txt

[41] Milbert, D. (1971) Earth Tide FORTRAN Code.

[42] Aleksandrov, L. and Mavrodiev, S. (1976) The Dependence of High-Energy Hadron-Hadron Total Cross-Section on Quantum Numbers. Dubna, Preprint JINR E2-9936.

[43] Aleksandrov, L. (1971) Regularized Ccomputational Process of Newton-Kantorovich Type. Computational Mathematics and Mathematical Physics, 1, 36-43.

[44] Aleksandrov, L. (1973) The Program REGN (Regularized Gauss-Newton Iteration Method) for Solving Nonlinear Systems of Equations. Comm. JINR P5-7259, Dubna, PSR 165 RSIK ORNL, Oak Ridge, Tennessee, USA, 1983.

[45] Aleksandrov, L., Mavrodiev, S. and Sissakian, A.N. (2005) On the Investigation of Some Nonlinear Problems in High Energy Particles Phenomenology and Cosmic Ray Physics. 


\section{Application 1}

Table 2. Fit data.

\begin{tabular}{|c|c|c|c|c|c|c|c|c|c|c|c|}
\hline St1St2 & Date & Lat & Long & Depth & Mag SChtM & Distance R & TimeDiff & PrecSignal & Th & Res & Def \\
\hline & MM.DD.YYYY & & & $\mathrm{km}$ & $\mathrm{J} / \mathrm{km}^{2}$ & $100 \mathrm{~km}$ & Day & & & (Expt-Th)/Expt & Expt-Th \\
\hline 1 KNYKAK & 7.20 .2010 & 34.28 & 135.533 & 34.28 & $4.902 .70 \mathrm{E}+06$ & 6.13 & 2.25 & $8.81 \mathrm{E}+00$ & $8.37 \mathrm{E}+00$ & 0.05 & 0.44 \\
\hline 2 KAKKNY & 7.20 .2010 & 34.28 & 135.533 & 34.28 & $4.904 .20 \mathrm{E}+06$ & 4.75 & 2.27 & $4.76 \mathrm{E}+00$ & $5.24 \mathrm{E}+00$ & -0.10 & -0.48 \\
\hline 3 KNYKAK & 1.1 .2012 & 31.456 & 138.072 & 31.46 & $6.808 .20 \mathrm{E}+08$ & 6.96 & 0.18 & $8.00 \mathrm{E}+00$ & $7.67 \mathrm{E}+00$ & 0.04 & 0.33 \\
\hline 4 KAKKNY & 1.1.2012 & 31.456 & 138.072 & 31.46 & $6.801 .10 \mathrm{E}+09$ & 5.66 & 0.80 & $4.54 \mathrm{E}+00$ & $5.03 \mathrm{E}+00$ & -0.11 & -0.49 \\
\hline 5 KNYKAK & 4.12 .2013 & 34.369 & 134.828 & 34.37 & $5.808 .00 \mathrm{E}+07$ & 5.75 & 2.42 & $2.26 \mathrm{E}+00$ & $4.06 \mathrm{E}+00$ & -0.80 & -1.80 \\
\hline $6 \mathrm{KAKKNY}$ & 4.12 .2013 & 34.369 & 134.828 & 34.37 & $5.809 .30 \mathrm{E}+07$ & 5.29 & 2.42 & $2.77 \mathrm{E}+00$ & $3.34 \mathrm{E}+00$ & -0.20 & -0.57 \\
\hline 7 MMBKAK & 6.27 .2010 & 41.662 & 141.657 & 41.66 & $5.303 .00 \mathrm{E}+07$ & 3.25 & 2.44 & $4.22 \mathrm{E}+00$ & $3.54 \mathrm{E}+00$ & 0.16 & 0.68 \\
\hline 8 ММBКАК & 6.27 .2010 & 41.662 & 141.657 & 41.66 & $5.303 .00 \mathrm{E}+07$ & 3.25 & 2.44 & $2.62 \mathrm{E}+00$ & $3.54 \mathrm{E}+00$ & -0.35 & -0.92 \\
\hline 9 MMBКАК & 7.4.2010 & 39.697 & 142.369 & 39.70 & $6.305 .70 \mathrm{E}+08$ & 4.93 & 1.41 & $5.50 \mathrm{E}+00$ & $4.84 \mathrm{E}+00$ & 0.12 & 0.66 \\
\hline 10 KAKMMB & 7.4.2010 & 39.697 & 142.369 & 39.70 & $6.307 .20 \mathrm{E}+08$ & 4.31 & 0.30 & $2.73 \mathrm{E}+00$ & $5.30 \mathrm{E}+00$ & -0.94 & -2.60 \\
\hline 11 MMBKAK & 8.10 .2010 & 39.406 & 143.148 & 39.41 & $5.901 .40 \mathrm{E}+08$ & 5.09 & 0.79 & $4.45 \mathrm{E}+00$ & $4.53 \mathrm{E}+00$ & -0.02 & -0.08 \\
\hline 12 KAKMMB & 8.10 .2010 & 39.406 & 143.148 & 39.41 & $5.901 .80 \mathrm{E}+08$ & 4.39 & 0.19 & $5.83 \mathrm{E}+00$ & $4.68 \mathrm{E}+00$ & 0.20 & 1.20 \\
\hline 13 MMBКАK & 9.1 .2010 & 37.925 & 141.788 & 37.93 & $5.206 .50 \mathrm{E}+06$ & 6.96 & 1.81 & $1.45 \mathrm{E}+00$ & $2.55 \mathrm{E}+00$ & -0.76 & -1.10 \\
\hline 14 KAKMMB & 9.1 .2010 & 37.925 & 141.788 & 37.93 & $5.203 .90 \mathrm{E}+07$ & 2.36 & 1.78 & $4.37 \mathrm{E}+00$ & $4.11 \mathrm{E}+00$ & 0.06 & 0.26 \\
\hline 15 MMBKAK & 12.6.2010 & 40.904 & 142.967 & 40.90 & $5.701 .30 \mathrm{E}+08$ & 3.49 & 0.79 & $5.67 \mathrm{E}+00$ & $5.91 \mathrm{E}+00$ & -0.04 & -0.24 \\
\hline 16 KAKMMB & 12.6.2010 & 40.904 & 142.967 & 40.90 & $5.705 .50 \mathrm{E}+07$ & 5.73 & 0.77 & $5.52 \mathrm{E}+00$ & $4.36 \mathrm{E}+00$ & 0.21 & 1.20 \\
\hline 17 MMBKAK & 6.8 .2014 & 39.164 & 141.709 & 39.16 & $5.208 .10 \mathrm{E}+06$ & 5.67 & 2.70 & $4.34 \mathrm{E}+00$ & $4.05 \mathrm{E}+00$ & 0.07 & 0.29 \\
\hline 18 KAKMMB & 6.8 .2014 & 39.164 & 141.709 & 39.16 & $5.201 .70 \mathrm{E}+07$ & 3.53 & 1.62 & $4.70 \mathrm{E}+00$ & $5.53 \mathrm{E}+00$ & -0.18 & -0.83 \\
\hline 19MMBKAK & 3.11 .2011 & 38.297 & 142.373 & 38.30 & $9.003 .90 \mathrm{E}+12$ & 6.43 & 0.29 & $5.94 \mathrm{E}+00$ & $7.23 \mathrm{E}+00$ & -0.22 & -1.30 \\
\hline 20 KAKMMB & 3.11 .2011 & 38.297 & 142.373 & 38.30 & $9.001 .50 \mathrm{E}+13$ & 3.01 & 0.23 & $9.20 \mathrm{E}+00$ & $8.05 \mathrm{E}+00$ & 0.13 & 1.20 \\
\hline $21 \mathrm{MMBKAK}$ & 5.5 .2011 & 38.17 & 144.032 & 38.17 & $6.001 .30 \mathrm{E}+08$ & 6.39 & 0.18 & $4.20 \mathrm{E}+00$ & $3.74 \mathrm{E}+00$ & 0.11 & 0.46 \\
\hline 22 KAKMMB & 5.5 .2011 & 38.17 & 144.032 & 38.17 & $6.003 .10 \mathrm{E}+08$ & 4.03 & 1.21 & $2.60 \mathrm{E}+00$ & $2.69 \mathrm{E}+00$ & -0.03 & -0.09 \\
\hline 23 MMBKAK & 6.22 .2011 & 39.955 & 142.205 & 39.96 & $6.702 .40 \mathrm{E}+09$ & 4.70 & 0.65 & $4.55 \mathrm{E}+00$ & $3.52 \mathrm{E}+00$ & 0.23 & 1.00 \\
\hline 24 KAKMMB & 6.22 .2011 & 39.955 & 142.205 & 39.96 & $6.702 .60 \mathrm{E}+09$ & 4.50 & 0.69 & $3.49 \mathrm{E}+00$ & $3.64 \mathrm{E}+00$ & -0.04 & -0.14 \\
\hline $25 \mathrm{MMBKAK}$ & 10.1.2012 & 39.808 & 143.099 & 39.81 & $6.103 .30 \mathrm{E}+08$ & 4.65 & 1.39 & $2.65 \mathrm{E}+00$ & $4.54 \mathrm{E}+00$ & -0.71 & -1.90 \\
\hline 26 KAKMMB & 10.1 .2012 & 39.808 & 143.099 & 39.81 & $6.103 .20 \mathrm{E}+08$ & 4.73 & 2.43 & $7.87 \mathrm{E}+00$ & $4.51 \mathrm{E}+00$ & 0.43 & 3.40 \\
\hline $27 \mathrm{MMBKAK}$ & 10.25 .2012 & 38.306 & 141.699 & 38.31 & $5.602 .80 \mathrm{E}+07$ & 6.58 & 1.98 & $5.73 \mathrm{E}+00$ & $4.30 \mathrm{E}+00$ & 0.25 & 1.40 \\
\hline 28 KAKMMB & 10.25 .2012 & 38.306 & 141.699 & 38.31 & $5.601 .20 \mathrm{E}+08$ & 2.67 & 1.93 & $2.94 \mathrm{E}+00$ & $4.23 \mathrm{E}+00$ & -0.44 & -1.30 \\
\hline 29 MMBKAK & 12.7 .2012 & 37.89 & 143.949 & 37.89 & $7.301 .00 \mathrm{E}+10$ & 6.70 & 0.94 & $5.38 \mathrm{E}+00$ & $5.41 \mathrm{E}+00$ & -0.01 & -0.03 \\
\hline 30 KAKMMB & 12.7.2012 & 37.89 & 143.949 & 37.89 & $7.302 .70 \mathrm{E}+10$ & 3.82 & 0.91 & $4.09 \mathrm{E}+00$ & $4.10 \mathrm{E}+00$ & 0.00 & -0.01 \\
\hline 31 MMBKAK & 7.10 .2013 & 39.638 & 141.705 & 39.64 & $5.301 .40 \mathrm{E}+07$ & 5.18 & 1.78 & $2.01 \mathrm{E}+00$ & $2.55 \mathrm{E}+00$ & -0.27 & -0.54 \\
\hline 32 KAKMMB & 7.10 .2013 & 39.638 & 141.705 & 39.64 & $5.302 .00 \mathrm{E}+07$ & 4.02 & 1.80 & $4.83 \mathrm{E}+00$ & $3.08 \mathrm{E}+00$ & 0.36 & 1.80 \\
\hline
\end{tabular}




\section{Application 2: The FORTRAN Version of Precursor Signal Function}

Function PrecSigTh (aMag, Depth, Distance)

IMPLICIT DOUBLE PRECISION (A-H, O-Z)

DIMENSION A (16)

DATA A/0.653118375493643180E+04, 0.239327649144353849E+02, $-0.441055930229294688 \mathrm{E}+03$, $-0.190062527379474363 \mathrm{E}+04, \&$

$-0.195894833103010524 \mathrm{E}+04,-0.514929656067517226 \mathrm{E}+04,-0.745560820661331309 \mathrm{E}+04$, $0.421788002467532533 \mathrm{E}+04, \&$

$0.420599862430744270 \mathrm{E}+04,0.319880390225624069 \mathrm{E}+04,-0.583971362592100718 \mathrm{E}+01$, $0.536940127973910677 \mathrm{E}+02, \&$

$0.510487668346017074 \mathrm{E}+03,0.287881656908347106 \mathrm{E}+00,-0.264988287827522662 \mathrm{E}+01$, $-0.614005144491253532 \mathrm{E}+02 /$

DepL $=\mathrm{d} \log ($ Depth $) ;$ DisL $=\mathrm{d} \log ($ Distance $)$

Str1 $=\mathrm{a}(2) * \mathrm{aMag}+\mathrm{a}(3) *$ DepL $+\mathrm{a}(4) *$ DisL

Str2 $=\mathrm{a}(5) / \mathrm{aMag}+\mathrm{a}(6) /($ DepL $+1 . \mathrm{d} 0)+\mathrm{a}(7) /($ DisL $+1 . \mathrm{d} 0)$

Str3 $=\mathrm{a}(8) / \mathrm{aMag}^{* * 2}+\mathrm{a}(9) /(\text { DepL }+1 . \mathrm{d} 0)^{* * 2}+\mathrm{a}(10) /(\mathrm{DisL}+1 . \mathrm{d} 0) * * 2$

Str4 $=\mathrm{a}(11) * \mathrm{aMag}^{* * 2}+\mathrm{a}(12) * \operatorname{DepL} * * 2+\mathrm{a}(13) * \operatorname{DisL}^{* * 2}$

Str5 $=\mathrm{a}(14) * a M a g * * 3+\mathrm{a}(15) * \operatorname{DepL}^{* * 3}+\mathrm{a}(16) * \mathrm{DisL}^{* * 3}$

PrecSigTh $=(\operatorname{eexp}(\mathrm{a}(1)+\operatorname{Str} 1+\operatorname{Str} 2+\operatorname{Str} 3+\operatorname{Str} 4+\operatorname{Str} 5))$

RETURN

END 